\title{
An investigation into the depth of penetration of low level laser therapy through the equine tendon in vivo
}

\author{
Teresa Ryan and Dr RKW Smith \\ The Royal Veterinary College, Hawkshead Lane, North Mymms, Hatfield, Hertfordshire, AL9 7TA,UK
}

\section{Corresponding author:}

Teresa Ryan Animal Physiotherapy, Ballinvrina, Emly, Co. Tipperary.

Email: vetphysio@iolfree.ie

Tel: $\quad$ +353 $877741287 ;+3536253130$

\begin{abstract}
Low level laser therapy (LLLT) is frequently used in the treatment of wounds, soft tissue injury and in pain management. The exact penetration depth of LLLT in human tissue remains unspecified. Similar uncertainty regarding penetration depth arises in treating animals. This study was designed to test the hypothesis that transmission of LLLT in horses is increased by clipping the hair and/or by cleaning the area to be treated with alcohol, but is unaffected by coat colour. A LLLT probe (810nm, 500mW) was applied to the medial aspect of the superficial flexor tendon of seventeen equine forelimbs in vivo. A light sensor was applied to the lateral aspect, directly opposite the laser probe to measure the amount of light transmitted. Light transmission was not affected by individual horse, coat colour or leg. However, it was associated with leg condition $(F=4.42, p=0.0032)$. Tendons clipped dry and clipped and cleaned with alcohol, were both associated with greater transmission of light than the unprepared state. Use of alcohol without clipping was not associated with an increase in light transmission. These results suggest that, when applying laser to a subcutaneous structure in the horse, the area should be clipped and cleaned beforehand.
\end{abstract}

Key words: low, level, laser, therapy, equine, tendon

Irish Veterinary Journal Volume 60 Number 5, 295-299, 2007

\section{Introduction}

Low level laser therapy (LLLT) is a popular modality in the physiotherapeutic management of human and animal patients. LASER ('light amplification by the stimulated emission of radiation') differs from ordinary light in its unique properties of monochromacity (single wavelength), coherence (waves in phase) and collimation (waves in parallel). As a result, it can deliver large amounts of energy to a small region over a short period of time (Kitchen and Partridge, 1991; Low and Reed, 2000). The use of low powered laser $\left(<500 \mathrm{~mW},<35 \mathrm{~J} / \mathrm{cm}^{2}\right.$, typical wavelengths of $600-1300 \mathrm{~nm}$ ) in the management of pain, wound healing and soft tissue injury was developed in the 1960s and has grown steadily since (Baxter, 2002).

Low level laser therapy is believed to have photochemical rather than thermal effects because low irradiation levels are used and no appreciable temperature rise takes place (Kitchen and Partridge, 1991). The photochemical theory, which is not yet universally accepted, postulates that the absorbed light interacts with chromophores (organic molecules) which in turn modulate cellular activities (Beckerman et al., 1992; Chartered Society of Physiotherapists, 1998; Baxter, 1999).

Research, therefore, centres on the cellular effects of laser as well as the effects that lasers have on wound healing, pain and musculoskeletal conditions. Cellular research has demonstrated that LLLT reduced experimentally induced inflammation by $20-30 \%$ and that wavelengths of 660 , 820 and $870 \mathrm{~nm}$ encouraged macrophages to stimulate fibroblast proliferation (Young et al., 1989; Honmura et al., 1992).

Clinically, LLLT is perceived as effective in the acceleration of wound healing (Baxter et al., 1991). A meta-analysis (Beckerman et al., 1992) and a Cochrane review (Flemming and Cullum, 2003) drew no conclusions regarding the efficacy of LLLT in skin disorders and venous leg ulcers respectively. Controlled trials on animal wounds treated with laser revealed varying degrees of success (Kaneps et al., 1984; Fretz and Li, 1992; Lucroy et al., 1999; Petersen et al., 1999). Two recent studies reported pain relief in both RA (rheumatoid arthritis) and fibromyalgia patients post irradiation with LLLT while a meta-analysis established no effect (Gam et al., 1993; Brosseau et al., 2003; Gur et al., 2003). In the equine model, Martin and Kilde (1987) demonstrated the alleviation of back pain in a non-controlled study. Finally, a Cochrane review of the use of $904 \mathrm{~nm}$ laser in musculoskeletal conditions concluded that LLLT appeared effective for pain relief and quicker functional recovery (de Bie et al., 1996). Sharma et al. (2002) displayed an ultrasound assessed decrease in tendon diameter of tenosynovitis diagnosed tendons, after laser application. Laser was no more effective than glycosaminoglycan or conservative management in treating 
superficial flexor tendon injuries in racehorses (Marr et al., 1993).

It is difficult to compare results of the various studies into laser therapy as parameters, when fully recorded, often vary (Kitchen and Partridge, 1991; Baxter, 2002). Different conditions are treated, different dosages utilised and different outcome measures are recorded. Investigative findings are ambiguous. For practically every supportive trial, there is a contradictory counterpart. Laser appears a popular therapy lacking sufficient supportive research (Vasseljen et al., 1992; Gam et al., 1993; Saunders, 1995). However, as Basford (1989) states, there exists enough evidence to justify the continued investigation of this mode of therapy. Practising physiotherapists surveyed corroborated the beneficial clinical effects of LLLT (Baxter, 1991). The recent extension of FDA (Federal Drug Agency, USA) approval to LLLT also illustrates this (Baxter, 2004).

As previously mentioned, penetration depth is one of the uncertainties pertaining to laser parameters. It is accepted and proven that penetration depth is a wavelength dependent property. Longer wavelengths will penetrate further (Kolari, 1985; Kolarova et al., 1999; Enwemeka, 2003). As a result, visible red laser light is used to treat wounds while infrared laser light is used for deeper musculoskeletal conditions. Nevertheless, energy density applied to the target tissues is unknown as the result of uncertainties pertaining to penetration depth (Low and Reed, 2000). Irradiation levels, in the form of energy density $\left(\mathrm{J} / \mathrm{cm}^{2}\right)$ at the surface applied, are commonly recorded by the clinician (Beckerman et al., 1992; Baxter, 1999). When LLLT is used in veterinary medicine, depth of penetration through hair and pigment is a major issue (Martin and Kilde, 1987; Bromiley, 1993; Marr et al., 1993; Petersen et al., 1999; Ramey and Basford, 2000). Currently, it is recommended that the irradiated area should be clipped and cleaned with an alcohol wipe before treatment (Bromiley, 1993; Low and Reed, 2000).

In conclusion, many questions remain unanswered regarding LLLT, including optimal dosimetry, mode of action, and number of treatments required etc. This study was undertaken in an attempt to address one of the above questions i.e., to what extent laser penetration in the equine model is affected by cleaning and clipping the area of application.

\section{Materials and methods}

Subjects were recruited from the resident equine population at the Hawkshead campus of the Royal Veterinary College, London. Permission was obtained from the relevant animal guardian. Horses with a history of, or obvious evidence of, forelimb tendon pathology were excluded. In all, seventeen sets of data were collected from the forelimbs of nine horses (one set of incomplete data was excluded). Three of the horses were grey, while the rest were bay. Five of the horses were thoroughbred (TB) while the rest were Irish Draught/TB crosses.
The laser therapy system used was a Thor DDII unit (Thor International Ltd, Amersham, Bucks, UK). A single point GaAlAs (gallium aluminium arsenide) laser probe, emitting a continuous beam of wavelength $810 \mathrm{~nm}$ and power $500 \mathrm{~mW}$, was used. In compliance with safety measures, the investigator and assistant wore protective goggles to prevent inadvertent ocular damage (Chartered Society of Physiotherapy, 1991; 1998). The light sensor used was a M3000 (FOE Ltd, Argyll, UK). This sensor was capable of detecting light waves in the $600-1300 \mathrm{~nm}$ wavelength and gave readings in microwatts $\mathrm{x} 10(\mathrm{uW} \times 10)$. This was precalibrated by the manufacturer. A standard vernier caliper (Mitutoyo (UK) Ltd, Hampshire, UK) was used. These calipers possess an accuracy of $0-200 \mathrm{~mm}+/-0.03 \mathrm{~mm}$ and a graduation of $0.02 \mathrm{~mm} / 0.001$.

Alcohol solution was used to clean the horses' coats. It was also used to clean the horses' skin after clipping. Electric clippers (number 30 blades) were used to clip the horses' skin. A preliminary study tested light penetration through the tendons of six subjects. These were tendons of varying thickness and coat colour. Results indicated that the light sensor was sensitive enough to detect changes in penetration of light through various equine tendons. It also suggested that the readings should be taken after sunset to minimise ambient light. Each horse was restrained with a head collar and lead rope in a loose box with an attendant and some loose hay. Measurements were conducted with the animal either standing on a rubber mat or a shallow bed of shavings and with the animal standing as 'square' as possible i.e., equal weight bearing on all four legs. Tendon lateromedial dimensions were gauged using the vernier calipers. This was measured at the junction of the distal third and proximal two-thirds of the superficial digital flexor tendon (SDF) as this is an easily identifiable site and is a frequent site of tendon injury (Kaneps et al., 1984). The therapeutic laser probe was applied at the medial aspect of the SDF of the horse's forelimb, at the junction of the distal third and proximal two thirds. This was done using the contact technique: firmly, perpendicular to the skin with slight indentation of the skin and by the same investigator each time (Baxter, 1994). The light sensor was then held in contact, directly opposite the laser probe, on the lateral aspect of the SDF. The two were maintained in position until the sensor delivered a reading. This was repeated three times and the mean measurement recorded.

Following findings from the preliminary study, a particular sequence was followed with each subject:

1. Measurement with the leg untreated (i.e., dry and dirty).

2. Measurement after the leg (i.e., that portion of the leg) was cleaned with alcohol solution and was still wet.

3. Measurement after the leg was cleaned with alcohol solution and had dried.

4. Measurement with the surrounding hair clipped.

5. Measurement with the clipped leg cleaned with alcohol solution and still wet.

Results were presented using tables and graphs. Analysis 
was by multiway analysis of variance with 'light transmitted' as the dependent variable and colour (grey or bay), horse, leg (right or left) and condition (dry, alcohol wet, alcohol dry, clipped dry or clipped wet) as the independent variables. The variable 'leg' was nested in the variable 'horse' and the variable 'horse' was nested in the variable 'colour'. All significance tests were two sided (Petrie and Sabin, 2000).

\section{Results}

The results of the tests performed have been summarised in Tables 1 and 2.

Simple cleaning of the hair and skin surrounding the tendon with alcohol, caused a general increase in penetration of light through the tendons $(\mathrm{p}=0.5762)$ (Figure 1, see p277). Readings which failed to register on the light sensor (i.e., those which produced a reading of 0 ) would indicate that the laser light introduced had been completely absorbed by the tendon and that none of this light had penetrated to the other side.

\section{Discussion}

The current mode of application of laser therapy is through the animal's coat, without any preparation (McKibbin and Paraschak, 1984; Martin and Kilde, 1987; Marr et al., 1993). However, results of this study suggest this to be the most inefficient way of applying laser. In the treatment of wounds, depth of penetration is not a major issue as the target tissue is superficial and exposed. However, LLLT is also advocated in the treatment of pain, soft tissue injuries and trigger points (Bromiley, 1993). In order for the laser to penetrate to the target tissue e.g., the centre of the superficial flexor tendon for a core lesion, it is necessary for the light to penetrate through hair, skin, subcutaneous tissue and the tendon.

With the majority of cases, cleaning the area of application with alcohol solution caused an increase in the amount of light penetrating through. However, when analysed, a non-significant $\mathrm{p}$ value of 0.5428 is returned. Low and Reed (2000) recommend that the skin of the (human)

Table 1: Lateromedial dimensions (diameter) of tendons used in study and average light transmitted through tendon $(\mathrm{uWx} 10, \mathrm{n}=9)$

\begin{tabular}{|c|c|c|c|c|c|c|c|c|c|c|c|c|c|c|c|c|c|}
\hline & Horse no. 1 & \multicolumn{2}{|c|}{ Horse no. 2} & \multicolumn{2}{|c|}{ Horse no. 3} & \multicolumn{2}{|c|}{ Horse no. 4} & \multicolumn{2}{|c|}{ Horse no. 5} & \multicolumn{2}{|c|}{ Horse no. 6} & \multicolumn{2}{|c|}{ Horse no. 7} & \multicolumn{2}{|c|}{ Horse no. 8} & \multicolumn{2}{|c|}{ Horse no. 9} \\
\hline Horse colour & Grey gelding & Grey & gelding & Grey & elding & Bay g & elding & Bay $\varepsilon$ & elding & Bay m & are & Bay m & are & Bay ge & Iding & Bay ge & ding \\
\hline $\begin{array}{l}\text { CASE } \\
(\mathrm{R}=\text { right leg, } \\
\mathrm{L}=\text { left leg) }\end{array}$ & $1(\mathrm{R})$ & $2(R)$ & $3(L)$ & $4(R)$ & $5(\mathrm{~L})$ & $6(\mathrm{R})$ & $7(\mathrm{~L})$ & $8(R)$ & $9(L)$ & $10(R)$ & $11(\mathrm{~L})$ & $12(\mathrm{R})$ & $13(\mathrm{~L})$ & 14(R) & 15(L) & $16(\mathrm{R})$ & $17(\mathrm{~L})$ \\
\hline Diameter (cm) & 2.8 & 3.5 & 3.7 & 2.9 & 3.5 & 3 & 3.1 & 2 & 2 & 2 & 2 & 2.2 & 2.4 & 2.2 & 2 & 2.3 & 2.4 \\
\hline $\begin{array}{l}\text { Average light } \\
\text { transmitted } \\
(\mathrm{uW} \times 10)\end{array}$ & 0.28 & 0.3 & 0.23 & 0.53 & 1.81 & 0.24 & 0.21 & 0.14 & 0.14 & 0.25 & 0.28 & 0.03 & 0.02 & 0.05 & 0.06 & 0 & 0.10 \\
\hline
\end{tabular}

Table 2: Mean amount of light ( $\mathrm{uWx} \times 10)$ transmitted through the tendon: grey subjects compared with bay subjects $(\mathrm{n}=9)$

\begin{tabular}{|c|c|c|}
\hline & \multicolumn{2}{|c|}{$\begin{array}{l}\text { Mean amount of light transmitted } \\
(\mathrm{uW} \times 10)\end{array}$} \\
\hline & $\begin{array}{l}\text { Grey }(n=5) \\
\text { Mean lateromedial } \\
\text { dimensions } \\
\text { (diameter) } 3.28 \mathrm{~cm}\end{array}$ & $\begin{array}{l}\text { Bay }(n=12) \\
\text { Mean lateromedial } \\
\text { dimensions } \\
\text { (diameter) } 2.3 \mathrm{~cm}\end{array}$ \\
\hline Dry i.e., untreated & 0.01 & 0 \\
\hline $\begin{array}{l}\text { Cleaned with alcohol } \\
\text { (wet) }\end{array}$ & 0.30 & 0.01 \\
\hline $\begin{array}{l}\text { Cleaned with alcohol } \\
\text { (dry) }\end{array}$ & 0.25 & 0.04 \\
\hline Clipped & 1.24 & 0.18 \\
\hline $\begin{array}{l}\text { Clipped and cleaned } \\
\text { with alcohol }\end{array}$ & 1.12 & 0.28 \\
\hline
\end{tabular}

There was a similar non-significant increase in the degree of penetration of light when the same tendon was remeasured after the alcohol solution was allowed to dry ( $\mathrm{p}=0.5428$ ) (Figure 2, see p277). Clipping of the hair covering the tendon increased light transmission through the tendon in all cases $(\mathrm{p}=0.0043)$ (Figure 3, see p277). The most pronounced increase in light penetration through the tendon was noted when the exposed skin of the clipped leg was cleaned with alcohol solution (clipped [+wet alcohol]), ( $\mathrm{p}=0.0023)$ (Figure 4, see p277). patient should be cleaned with an alcohol wipe prior to treatment. Subsequent to this, the surface of the tendon was clipped. This was in compliance with the recommendation of Bromiley (1993) that the area to be treated should be shaved beforehand. There was an increase in the depth of penetration of laser through all clipped tendons, compared with the untreated tendons $(\mathrm{p}=0.0043)$. This would indicate that clipping has a greater impact on laser penetration than cleaning with alcohol solution alone. Following this, the clipped tendon was cleaned with alcohol solution and a cotton swab. Again there was an increase in penetration, compared with the untreated tendon $(\mathrm{p}=0.0023)$.

On average, a greater amount of light was transmitted through the tendons of the grey subjects compared with the bay subjects. This was notwithstanding the difference in lateromedial dimensions, with an average grey tendon dimension of $3.28 \mathrm{~cm}$ compared with $2.30 \mathrm{~cm}$ for the bay horses. However, these results were not significant. The results of this study would appear to indicate that clipping the area to be irradiated before laser treatment would increase the depth of penetration of the light. This is most relevant in the treatment of pain and musculoskeletal conditions e.g., treating a muscle injury, where one is aiming to influence deeply seated structures. Furthermore, the results would suggest that even cleaning the coat and skin over the area to be irradiated with alcohol 


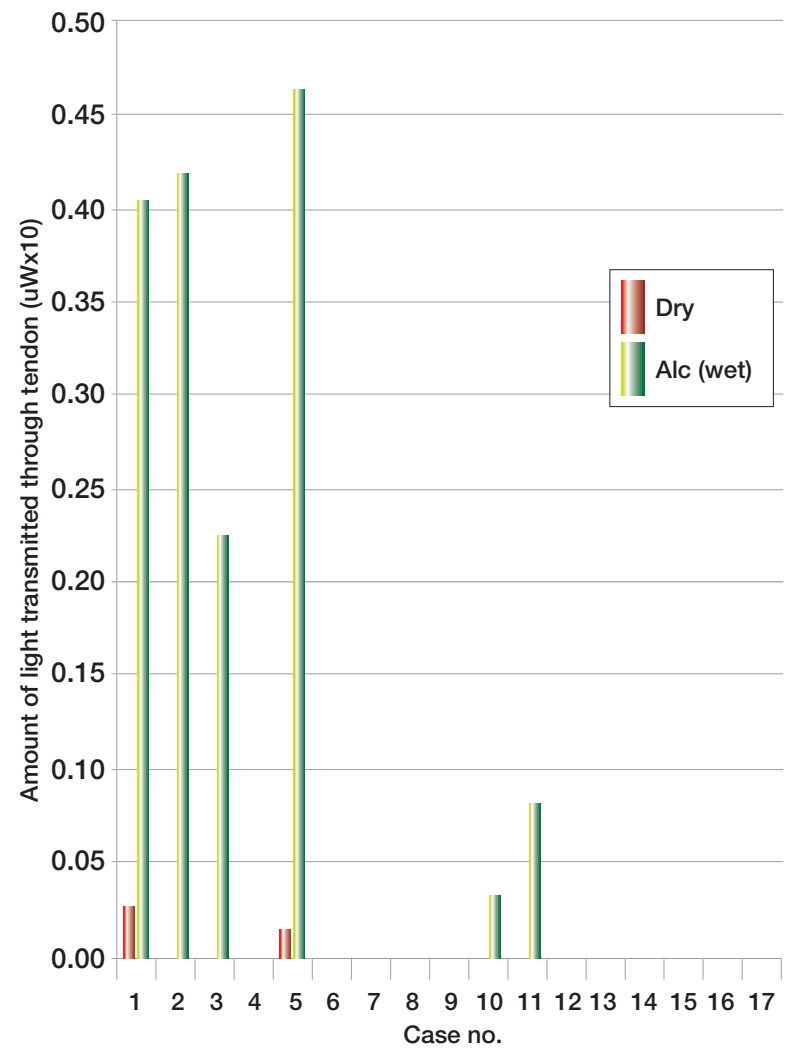

Figure 1: Penetration of dry vs alcohol (wet).

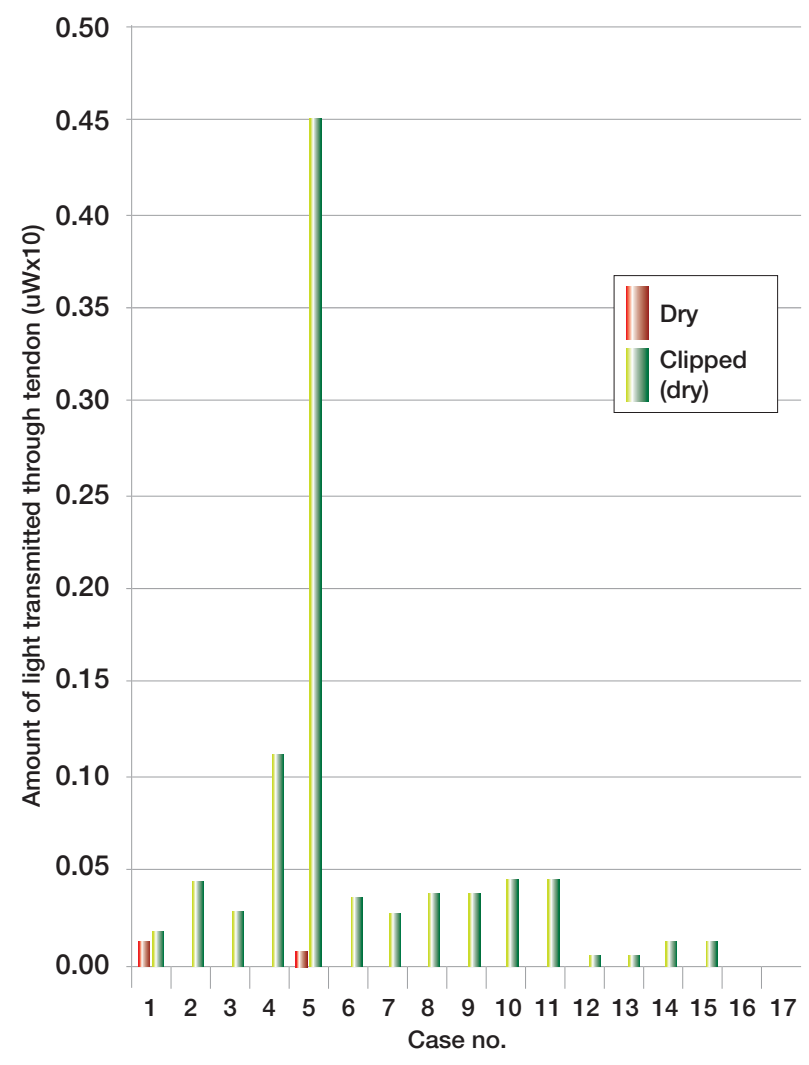

Figure 3: Penetration of dry vs clipped (dry).

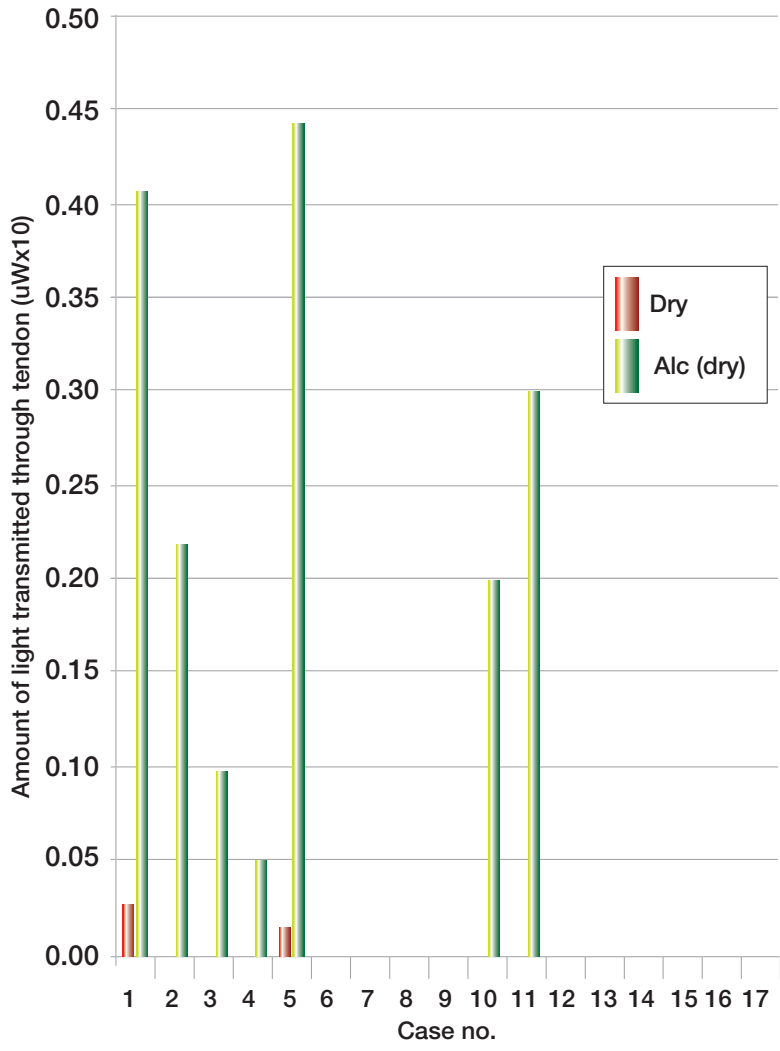

Figure 2: Penetration of dry vs alcohol (dry).

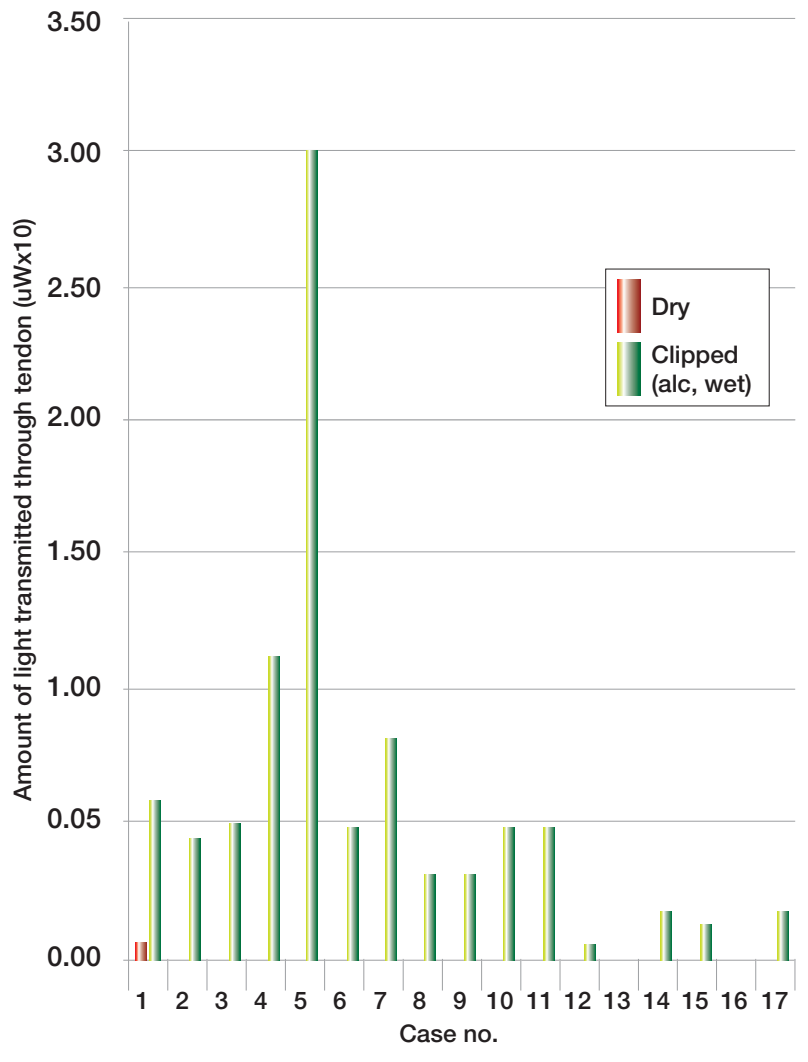

Figure 4: Penetration of dry vs clipped (alcohol, wet). 
solution would have a positive effect on light penetration. This may sometimes be indicated where clipping is out of the question (e.g., show animals). None of these recommendations are novel. Cleaning of the area to be treated has already been advised (Low and Reed, 2000). Furthermore, it has been stipulated that the hair covering the area to be treated should be clipped (Bromiley, 1993). However this does not appear to be adhered to clinically (Marr et al., 1993). In addition, this area does not appear to have been investigated previously.

In conclusion, based on the results of this research, it is to be recommended that the practitioner clips and cleans the area to be irradiated prior to treatment with LLLT.

\section{Acknowledgements}

The authors wish to acknowledge the assistance of Thor Lasers, Dr N.F. Horgan, RCSI, and staff and personnel at the Royal Veterinary College Hawkshead campus.

\section{References}

Basford, J.R. (1989). Low energy laser therapy: Controversies and new research findings. Lasers in Surgery and Medicine 9: 1-5.

Baxter, G.D. (1994). Therapeutic Lasers, Theory and Practice. $1^{\text {st }}$ edn. New York: Churchill Livingstone.

Baxter, G.D. (1999). Laser therapy seminar, Royal College of Surgeons in Ireland.

Baxter, G.D. (2002). Low-intensity laser therapy. In: Kitchen, S. and Bazin, S., eds. Electrotherapy: Evidence-Based Practice. $11^{\text {th }}$ edn. London: Churchill Livingstone. 171-190.

Baxter, G.D. (2004). Personal communication.

Baxter, G.D., Bell, A.J., Allen, J.M. and Ravey, J. (1991). Low level laser therapy: Current clinical practice in Northern Ireland. Physiotherapy 77(3): 171- 178 .

Beckerman, H., de Bie, R.A., Bouter, L.M., De Cuyper, H.J. and Oostendorp, R.A. (1992). The efficacy of laser therapy for musculoskeletal and skin disorders: A criteria based meta-analysis of randomised clinical trials. Physical Therapy 72(7): 483-491.

Bromiley, M. (1993). Equine Injury, Therapy and Rehabilitation. $2^{\text {nd }}$ edn. Oxford: Blackwell Science.

Brousseau, L., Welch, V., Wells, G., deBie, R., Gam, A., Harman, K., Morin, M., Shea, B. and Tugwell, P. (2003) Low level laser therapy (Classes I, II and III) for treating rheumatoid arthritis (Cochrane review). In: The Cochrane Library, 4, Chichester: John Wiley and Sons. Chartered Society of Physiotherapy (1991). Guidelines for the safe use of lasers in physiotherapy. Physiotherapy 77(3): 169-171.

Chartered Society of Physiotherapy (1998). Laser therapy. In: Standards for the use of electrophysical modalities and guidance in their application. Chartered Society of Physiotherapy Information Resource Centre. 27-30. De Bie, R., Verhagen, A., Lenssen, T., de Vet, R. and van den Wildenberg, F. (1996). Oral presentation: Efficacy of $904 \mathrm{~nm}$ laser therapy in musculoskeletal disorders: a systematic review. In: The Cochrane Library. Chichester: John Wiley and Sons.

Enwemeka, C.S. (2003). Attenuation and penetration of visible $632.8 \mathrm{~nm}$ and invisible infra-red $904 \mathrm{~nm}$ light in soft tissues. Laser Therapy Journal. 13: 16.

Flemming, K. and Cullum, N. (2003). Laser therapy for venous leg ulcers (Cochrane methodology review). In: The Cochrane Library, 4, Chichester,
UK: John Wiley and Sons.

Fretz, P.B. and Li, Z. (1992). Low energy laser irradiation treatment for second intention wound healing in horses. Canadian Veterinary Journal 33: 650-653.

Gam, A. N., Thorsen, H. and Lonnberg, F. (1993). The effect of low level laser therapy on musculoskeletal pain: a meta-analysis. Pain 53: 63-66. Gur, A., Cosut, A., Sarac, A.J., Cevik, R., Nas, K. and Uyar, A. (2003). Efficacy of different therapy regimes of low power laser in painful osteoarthritis of the knee: a double blind and randomised controlled trial. Lasers in Surgery and Medicine 33(5): 330-338.

Honmura, A. Yanase, M., Obata, J. and Haruki, E. (1992). Therapeutic effect of Ga-Al-As diode laser irradiation on experimentally induced inflammation in rats. Lasers in Surgery and Medicine. 12: 441-444.

Kaneps, A.J., Hultgren, B.D., Riebold, T.W. and Shires, G.M.H. (1984). Laser therapy in the horse: Histopathological response. American Journal of Veterinary Research 45(3): 581-582.

Kitchen, S.S. and Partridge, C.J. (1991). A review of low level laser therapy. Physiotherapy 77(3): 161-168.

Kolari, PJ (1985). Penetration of unfocused laser light into the skin. Archives of Dermatological Research. 277: 342-344.

Kolarova, H., Ditrichova, D. and Wagner, J. (1999). Penetration of the laser light into the skin in vitro. Lasers in Surgery and Medicine. 24: 231235.

Low, J. and Reed, A. (2000). Electrotherapy Explained: principles and practice. $3^{\text {rd }}$ edn. Oxford: Butterworth Heinemann.

Lucroy, M.D., Edwards, B.F. and Madewell, B.R. (1999) Low-intensity laser light-induced closure of a chronic wound in a dog. Veterinary Surgery 28: 292-295.

Marr, C.M., Love, J.S., Boyd, Q. and McKellar, Q. (1993). Factors affecting the clinical outcome of injuries to the superficial digital flexor tendon in National Hunt and point-to-point racehorses. The Veterinary Record. 132: 476-479.

Martin, B.J. and Kilde, A.M. (1987). Treatment of chronic back pain in horses: Stimulation of acupuncture points with a low powered infrared laser. Veterinary Surgery 16(1): 106-110.

McKibbin, L.S. and Paraschak, D. (1984). Use of laser light to treat certain lesions in standardbreds. Modern Veterinary Practice 65(3): 210-213. Mester, A.F. and Mester, A. (1989). Wound healing. Laser Therapy 1(1): 7-15.

Petersen, S.L., Botes, C., Olivier, A. and Guthrie, A.J. (1999). The effect of low level laser therapy (LLLT) on wound healing in horses. Equine Veterinary Journal 31(3) 228-231.

Petrie, A. and Sabin, C. (2000). Medical Statistics at a glance. Oxford: Blackwell Scientific Publications.

Ramey, D.W. and Basford, J.R. (2000). Laser therapy in horses. Compendium on Continuing Education for the Practicing Veterinarian 22(3): 263-272.

Saunders, L. (1995). The efficacy of low level laser therapy in supraspinatus tendonitis. Clinical Rehabilitation 9: 126-134. Sharma, R., Thukral, A., Kumar, S. and Bhargava, S.K. (2002). Effect of low level lasers in de Quervains tenosynovitis - a prospective study with ultrasonographic assessment. Physiotherapy 88(12): 714-775.

Vasseljen, O., Hoeg, N., Kjeldstad, B., Johnsson, A. and Larsen, S. (1992). Low level laser versus placebo in the treatment of tennis elbow. Scandinavian Journal of Rehabilitation in Medicine 24: 37-42.

Young, S, Bolton, P., Dyson, M., Harvey, W. and Diamantopoulos, C. (1989). Macrophage responsiveness to light therapy. Lasers in Surgery and Medicine 9:497-505. 